\title{
Geotechnical and Numerical analysis of Bcharreh Landslide stability
}

\author{
Diala Tabbal ${ }^{1}$, Marwa Saleh $^{1}$, and Hiba Bashir $^{1}$ \\ Beirut Arab University (BAU), Department of Civil Engineering, Tripoli, Lebanon
}

\begin{abstract}
The aim of this study is to shed light on a real stability problem within the region of Bcharreh located in North of Lebanon where roads have no protection against landslides. An attempt for landslide assessment that occurred in November 2016 is presented in order to analyse the different factors behind the landslide and find the trigger factor affecting the stability of the slope. The characterization of soil properties along the slope is done based on geotechnical investigation, and data collection. The first part of work consists of site inspection and geotechnical investigation followed by a series of laboratory tests to evaluate the mechanical properties constituting the slope, in addition to collection of topographical and hydrogeological data. The second part presents the numerical analysis where a finite element model simulating the slope conditions is generated using Plaxis 2D in order to reproduce the process of landslides, to assess slope stability and determine the overall factor of safety in both dry and wet conditions. The contribution of each causal factor in prompting soil movement is then demonstrated and explained.
\end{abstract}

\section{Introduction}

Landslides represent a major natural hazard which can cause significant damage, economic loss, and loss of life. It becomes a source of concern for geotechnical engineers throughout the world.

In Lebanon, landslides becomes a serious geological hazard especially in rugged mountainous terrain where many impressive landslides have occurred and damages were sometimes very severe. Many attempts were done in this respect and focus on the conditions on the landslide phenomena giving a qualitative analysis to the main reasons of slope instability. Many regions were considered in the slope instability assessment such in Dahr el Baidar Slope [1,2], Hammana region [3,4], Broumanna [5], Kfarnabrakh [6], Aquoura [7].

In the North of Lebanon, the slope of a mountainous area in Bcharreh district has recently experienced a major landslide in November 2016. According to landslide hazard distribution map in Lebanon prepared by the World Health Organization [8], Bcharreh district falls in a high landslide risk zone.

No investigation of landslides assessment was done before for this area except a study done by [9], but the study was general and more descriptive. Therefore this area was selected in an attempt to analyze the factors affecting the stability of the slope through data 
collection and geotechnical investigations. A 2D finite element model is presented to show the behaviour of the slope under dry and wet conditions. Different major factors that control the stability of the slope will be analysed and the trigger factor is discussed.

\section{Concept of instability}

Landslide occurs when part of a natural slope is unable to support its own weight causing mass wasting and rock or soil movement. Slope failure can be a result of the convergence of a series of unfavorable stability conditions, both natural and human induced. Landslides and slope instability take place when the driving forces, which promote downward movement equal or exceed the strength of the earth materials that compose the slope. The state of a slope is determined through a common ratio called factor of safety (FS) such that:

$$
F S=\frac{\text { resisting stresses }(\text { or shear strength })}{\text { driving stresses }(\text { or shear stresses })}
$$

[10] classified the state of a slope to be either "stable", "marginally stable", or "actively unstable". A slope state may be altered due to a change in any of the causal factors. Factors that shift a slope from a stable to a marginally stable state are commonly referred to landslide preparatory causal factors. Whereas, a factor is considered as a trigger when it turns the slope into an actively unstable state. Usually one single triggering factor initiate the landslide despite of the abundance of the causal factors [11]. In Lebanon, the main factors that made the slope vulnerable to failure are: slope gradient, soil type, pluviometry and hydrogeological Factor [9].

\section{Site location}

The landslide occurred on the slope the mountain town called "Qnat" located in Bcharreh District in the North Governorate of Lebanon. This village is 33 Kilometers away from Tripoli and 107 kilometers away from Beirut with an altitude of 1150 meters above the sea level.

\section{Data collection and analysis}

The data concerning the site are collected from several sources, through the field visits and investigation, photos acquisition, previous research and discussions with local residents and members from Bcharreh municipality.

Therefore, a geotechnical investigation followed by laboratory testing are carried out in the area. Then geological, topographical and pluviometric maps of the sloped area are interpreted in order to understand the causes that leaded to slope failure and classify the main factors behind the landslide based on their degree of influence.

\subsection{Geology of Bcharreh region}

This geological study is extended from West to East starting from Chnata village, passing by Qnat, and ending in Qornet el Saouda. The geology of the studied area is characterized by the Jurassic and Cretaceous rock types with different structural features. Jurassic rocks are mainly existing in the valleys, namely Qadisha and Qannoubine. Whereas, Cretaceous formations are extended from villages above the valley up till the highest mountains of Qornet El Souda with an elevation of 3088 meters. 


\subsection{Geotechnical investigation}

In order to study the most probable causes leading to the slope failure, a field investigation in the region was conducted to evaluate the mass failure that took place. An experimental campaign as then carried out in the laboratory to determine soil engineering properties.

\subsubsection{Visual inspections}

The field observation showed that the soil is multi-layered with apparently 3 soil layers resting on a superposition of clayey and limestone formations. A rock zone exists at the right side of the slope profile behind the existing soil layers. The bedding planes of the rocks are inclined towards the slope creating then a potential slip surfaces in the rock. The slope profile is very high with steep inclination angles in some zones (Figure $1 a, b$ ). Part of the crest was eroded in the form of debris. The slided fragment is extended up to 11 meters in height and around 13 meters in width forming a triangular shape near the slope. The top of the slope was eroded and massive rocks were shattered on the surface within easy reach of road since roads have no protection against mass movement. Landslide movement has occured mainly by free fall, sliding and rolling. Rock fall was dominant in the higher elevations whereas debris flows, slides and soil flow dominated the lower elevations.
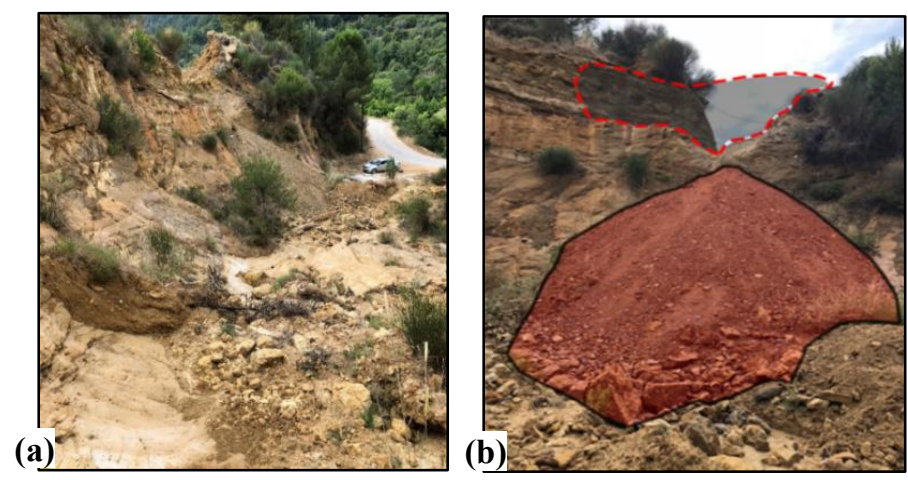

Fig. 1: (a) Landslide in Qnat near the main road, (b) Central part of the sliding zone

\subsubsection{Laboratory testing}

The study of material properties is important in stability analysis since the strength parameters indicate both the height and inclination that a slope can maintain when subjected to driving forces. In addition, the type of material can give an indication of the type of failure (e.g., debris flow, rock fall, and slump) [12]. Based on the above, Qnat landslide was classified as a rock fall and soil flow.

Four auger boreholes were drilled inside and beyond the slipped part of the slope. Locations of these boreholes are shown in figure 2. Then a series of laboratory tests were conducted to determine the soil engineering properties of the different layers along the slope. Soil classification is done based on USCS system. Analysis of data shows the existence of three main layers as follow: top layer consists of gravelly sand with a low plasticity index having the following parameters $\left(c^{\prime}=12 \mathrm{kPa}\right.$ and $\left.\varphi^{\prime}=35^{\circ}, \mathrm{PI}=3 \%\right)$. The layer below is composed of a mix of silt, clay and sand with a plasticity index $\mathrm{PI}=18 \%$ (c' $=$ $33 \mathrm{kPa}$ and $\varphi^{\prime}=22^{\circ}$ ). And the layer at the bottom of the slope is of clayey sand type $\left(c^{\prime}=35 \mathrm{kPa}\right.$ and $\left.\varphi^{\prime}=22^{\circ}, \mathrm{PI}=13 \%\right)$. First two layers are intercalated by silty sand with gravel layer with gravel $\left(\mathrm{c}^{\prime}=22 \mathrm{kPa}\right.$ and $\left.\varphi^{\prime}=28^{\circ}, \mathrm{PI}=10 \%\right)$. Rocks were assigned Mohr-Coulomb strength as well with zero tensile strength, $1000 \mathrm{KPa}$ cohesion and $20^{\circ}$ friction angle. 


\subsection{Topographical data}

The role of slope in landslide occurrence is evident, and it is important to define the slope limits for which the slope will be classified as strong and steep. Therefore, slope height and slope gradient at different levels are obtained after consulting the area by a surveyor using a GPS. The slope steepness is then classified with refer to [13] for measuring slope steepness. For instance, a slope is considered steep when the gradient is higher than $35^{\circ}$. Thus, the slope in our study is considered very strong and steep (Figure 2). Slope steepness and the associated mode of failure are coherent with the study made by [14].

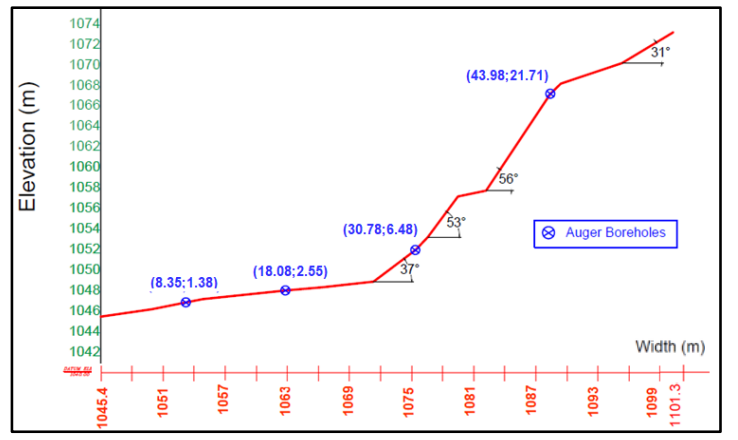

Fig. 2. Studied slope profile resulted from GPS instrument including the location of the boreholes.

\subsection{Pluviometry data}

Rainfall is the prevailing cause for groundwater changes that prompt movement in shallow landslides.It is an external stimuli that can trigger a slope and rend it from marginally stable to unstable. Intense rainfall can be one of the major factor in changing intergranular forces especially in case of undrained soil, in which the water is not allowed to flow out of the soil and decrease the friction between soil particles and its shear strength. According to "World Wide Travel Organisation", the average precipitation in Bcharreh for year 2016 is $845 \mathrm{~mm}$ which classifies Bcharreh, and particularly Qnat, as high pluviovemetry region. The Data was recorded from the nearest weather station located in Tripoli Lebanon.

\section{Numerical analysis}

The studied slope was modeled on PLAXIS software [15] using finite element model FEM. The model is $56 \mathrm{~m}$ long and $29 \mathrm{~m}$ high. Mohr-Coulomb model is used in the numerical simulation. Slope geometry, soil and rock properties are simulated based on the results of the geotechnical investigation described in the above sections (Figure 3).

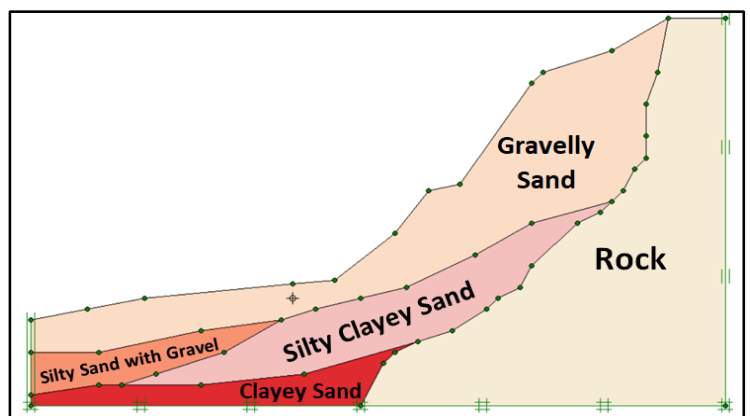

Fig. 3. Geometry of the slope simulated in a Plaxis 2D model 


\subsection{Stability analysis under dry conditions}

Initially, water table was not considered in the analysis. The factor of safety and the critical slip surface are then determined employing the phi-c reduction method (Figure 4-a). The factor of safety obtained after the model simulation in dry condition is equal to 1.15, which is less than 1.5 (desired value of FS), and the recorded horizontal displacement, Ux, at the top of the slope is $37 \mathrm{~cm}$. Therefore the studied slope, remains prone to further movements. This may be due to significant self-weight stresses. This constant application of stresses cause gradual damage of soil materials, which is known by "static fatigue".

Thus, the slope geometry plays a significant role in susceptibility of a slope to failure. The steeper a slope, the greater the self-weight stresses that are in operation. And this explains why the upper layer, having a slope of $71^{\circ}$ (greater than $45^{\circ}+\Phi / 2$ ), is mostly damaged and ruptured. It is mainly because gravity becomes stronger with increasing angle of the slope. This type of stresses can cause a slope to fail suddenly without any external factors. And this can explain the low factor of safety obtained in the dry season.

\subsection{Stability analysis under winter conditions}

The winter condition was activated by raising up the level of water up to 6 meters below the ground surface. The depth of water table was roughly estimated based on the surveys made with the residents and Qnat municipality on water levels recorded in wells drilled in the village. Results of numerical simulation show a greater horizontal displacement of 49 $\mathrm{cm}$ under winter conditions (34\% increase with respect to dry condition) at the head of the sliding zone with a lower factor of safety equal to 1.07 increases the slope instability risk and making the rainfall a triggering factor. Regarding the failure mechanisms, rotational slip is found for both cases but more expanded in winter conditions where the failure surface reach the toe of the slope (Figure 4-b). Failure after high rainfalls initiated with soil flow followed by successive slips. Rapid infiltration of water after individual storms cause numerous shallow slides where high water pressures can rapidly reach slip surfaces.

As the soil contains high content of fine-grained particles, the soil loses part of its cohesion upon saturation, changing then the state or consistency of materials and its strength parameters. The inter-particle forces and the associated friction throughout the length of the rupture surfaces will be consequently reduced in presence of water. Adding that water flow through rocks can dissolve some of the minerals that bind the rock together. The removal of cementing material decreases the cohesion of rocks and therefore slope's strength, preparing it for failure by mass movement.

Even though the groundwater table may not always be high, its fluctuations can cause a cyclic fatigue by going up and down altering the stability of the slope.
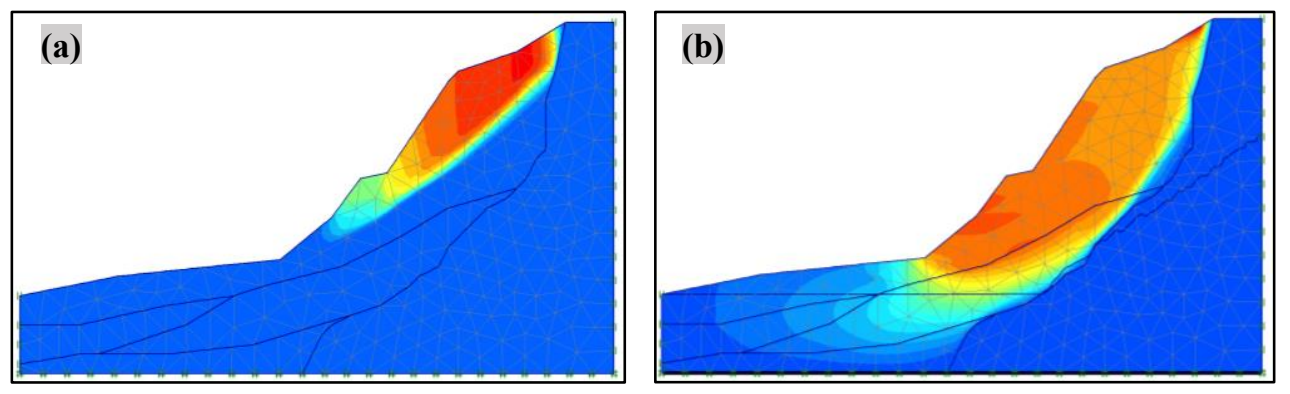

Fig. 4: Failure mechanisms for the case of (a) dry conditions $\left(F S=1.15 \& U_{x}=37 \mathrm{~cm}\right)$, (b) winter conditions $\left(\mathrm{FS}=1.07 \& \mathrm{U}_{\mathrm{x}}=49 \mathrm{~cm}\right)$ 


\section{Conclusion}

This paper presents a case study of an active that has occurred in 'Qnat' mountainous area located in Bsharreh district. Landslide comprised mainly rock flow followed by debris and soil flow. An attempt to understand the behavior of the unstable slope was shown. To do, a site investigation in the area was conducted followed by a series of laboratory tests. Then a finite element model of the slope was developed using Plaxis 2D to simulate the factors behind the slope sliding. Initial conditions showed that the slope is prone to failure under its self-weight, where FS was found to be 1.15. Simulations under wet conditions showed a further decrease of factor of safety making the groundwater fluctuations the triggering factor of our case study.

The steepness of the slope geometry along with the soil type make the slope exposed to static fatigue. Groundwater fluctuations, arising from water infiltration, induce a cyclic fatigue which influences the pore water pressures and changes the effective normal stresses. All the mentioned factors cause strength degradation by weakening the intact particles or the contacts between particles. Thus, strength degradation plays a major role in land movement, or may itself be the final failure trigger. Hence, a robust understanding of strength degradation with an accurate quantitative study is a must for landslide predictions in order to reduce the damage and find the suitable solution.

For a precise study, in situ sample disturbancy should be managed for its significant effect on the measured stress-strain behavior and the breakdown which may be caused to the clay structure. In addition, simulation of discontinuities should be incorporated in the numerical model. They can allow pathways for water seepage and influence the pore water conditions of the material causing further stress concentration on the slope stresses.

Results obtained indicate the need to take immediate engineering measures to prevent additional damages by suggesting slope reinforcement methods and evaluating their efficiency. Optimum solution will be selected taking into consideration different criteria such as: efficiency, durability, cost and environmental impact.

\section{References}

1. M. Rahhal, D. Abdel-Massih, J.Harb, F. Hage-Chehade, C. Abdallah, L. KhalafKeyrouz, G. Abou Jaoude, E. Ibrahim, G. Nasr,A. Sursock, 2ECEES, (2014)

2. T. Matar1, F. Hage Chehade, J. Harb, M. Rahhal, D. Youssef Abdel Massih, C. Abdallah, E. Ibrahim, L. Khalaf-Keyrouz, G. Nasr, G. Abou-Jaoude, and A. Sursock, COMPDYN, (2015)

3. C. Abdallah, F. Gomez, 2011. Workshop on the Applications of GNSS (2011)

4. M. Khawlie, H. Hassanain, Engineering Geology 20, 253-264 (1984)

5. A. Shaban, M. Khawlie, R. Bou Kheir, C. Abdallah Bull. Eng. Geol. Environ, 60, pp. 93-101, (2001)

6. C. El Mohtar, G. Abou Jaoude, C. Abdallah, J.Harb, GEER Report, 047 (2016)

7. C.Tavitian, Ph.D. thesis, University of Salford, 247p (1974)

8. World Health Organization, Landslide hazard distribution map, (2007)

9. R. Nini, Landslide susceptibility mapping, IJECT, 6, pp.161-171 (2015)

10. M.J. Crozier, T. Glade, Landslide hazard and risk, Wiley, pp. 1-40 (2005)

11. D.J. Varnes, Landslides, National Academy of Sciences, Special Report No. 176, , pp.11-33, (1978)

12. D.M. Cruden, C.D. Martin,9th. Asian Regional Conference IAEG, pp.46-55 (2013)

13. Barcelona Field Study Centre, Measuring Slope Steepness

14. A. Grant, J. Wartman, G. Abou-Jaoude. Eng. Geol. 212, pp. 146-160. (2016)

15. P.Vermeer, R.Brinkgreve "Plaxis Finite element code for soil and rock analyses"(1998) 